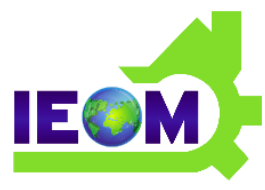
International Journal of Industrial Engineering and Operations Management (IJIEOM)
Volume 3, No. 1, October 2021
IEOM Society
International
pp. $16-32$

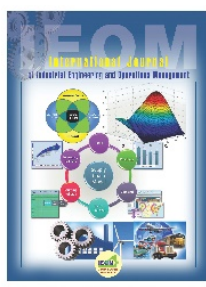

\title{
Assessment of Critical Failure Factors for Implementing Lean Six Sigma in Manufacturing Industry: A case study
}

\author{
Dr. Vikas Swarnakar \\ Department of Mechanical Engineering, National Institute of Technology, Raipur- 492010, Chhattisgarh, \\ INDIA \\ vikkiswarnakar@gmail.com \\ https://doi.org/10.46254/i.ieom.20210102
}

\begin{abstract}
In the present scenario manufacturing industries have been facing problem-related to cost, quality, and customer satisfaction. To overcome such problems, the organizations are ready to adopt continuous improvement (CI) approaches such as Lean Six Sigma (LSS) which keeps them stable when the demand for products or services fluctuates. LSS is a breakthrough improvement approach that helps to improve the bottom-line result of the company by utilizing its tools and techniques. The successful adaptation of the LSS approach provides a significant improvement in key metrics but deficiency of proper implementation shows a negative effect. To prevent such a situation, need to know about their failure factors. The objective of the present study is to assess the critical failure factors (CFFs) for LSS framework implementation in manufacturing organizations. The leading CFFs for LSS have been identified and selected through a structured literature review and expert opinion. The CFFs based model for LSS implementation has been developed using the Interpretative Structural Modelling and Matrice d' Impacts Croises Multiplication Appliquee a un Classement (ISM-MICMAC) approach. Previous studies related to such concerns have not developed a structural hierarchical model that is necessary to tackle CFFs towards the LSS implementation process. Such an interrelation helps decision-makers, planners to systematically guide about the barriers that affect the implementation process and help for further implementation success. The developed structured model will also help LSS practitioners, consultants, researchers to anticipate the potential CFFs to implement the LSS framework in their industry for continuous improvement and achieve a leading position in a competitive market.
\end{abstract}

ARTICLE INFO

\section{Introduction}

Manufacturing organizations are one of the rapidly growing sectors within India and have tremendous impacts on the Indian economy (Swarnakar et al., 2019c). India is $5^{\text {th }}$ biggest manufacturer within the globe with an overall manufacturing value added of over 420 billion US dollars in 2016. The average of seven percent growth has been achieved every year which accounts for 16 to 20 percent total gross domestic product (GDP) in India (The Hindu, Business Line, 2018). It also plays a lead role in generating employment (Malek and Desai, 2019; Swarnakar et al., 2020c). The Indian government aims to achieve $25 \%$ of gross domestic product share and 100 million new jobs for unemployed peoples in this sector by 2022 (Indian Industry Report, March 2020). To achieve these targets, the Indian government has been presently launched the "Make in India" program (Swarnakar et al., 2020a, d). The business condition of the manufacturing sector of India continues to remain positive (Indian Industry Report, March 2020) 
Today due to the increase in demands for quality products and services, manufacturing organizations are rapidly adopting continuous quality improvement approaches such as Lean manufacturing (LM), Total Quality Management (TQM), Six Sigma (SS), and Plan-Do-Check-Act (PDCA) approach for operational excellence (Swarnakar et al., 2019a, b). The Lean manufacturing approach is used to eliminate wastes, continuously improve quality, and create value for customers (Grasso, 2005; Swarnakar and Vinodh, 2016; Fullerton et al. 2014; Swarnakar et al., 2020b). Six Sigma is an approach that highlighted the variation in the manufacturing process and helps to reduce them through their statistical tools and techniques (Swarnakar and Vinodh, 2014; Vinodh and Swarnakar, 2015). The combination of these approaches (Lean Six Sigma) provides extensive benefits to the organization and enhance the bottom-line results (Swarnakar et al., 2019d). The concept of combining LSS principles began in the middle of the late 1990s (Swarnakar and Vinodh, 2014). The adaptation of the LSS approach maximizes the value of shareholders through continuous improvement (George and George, 2003). Numerous studies have reported the LSS framework implementation benefits such as an increase in production utilization rate, reduction in defects, quality improvement, improve production capacity, improvement in key metrics, eliminate nonvalue adding activities (Lee and Wei, 2010; Bhuiyan et al., 2006; Kumar et al., 2006; Vinodh et al., 2011; Vinodh et al., 2014; Chen and Lyu, 2009; Chakravorty and Shah, 2012; Waite, 2013, Swarnakar and Vinodh, 2016) The successful adaptation of LSS framework in any manufacturing industry resulted in benefits such as uninterrupted and defect-free production. It also helps to achieve a higher degree of competitiveness in a competitive market when implemented successfully. The deficiency of proper implementation will achieve the negative effects which cause decrease quality, dissatisfied customers, fluctuation in demands, and a negative image of the organization (Swarnakar et al., 2019b; 2020a). To prevent such a situation, need to know about the CFFs of LSS that affect the successful adaptation of the LSS framework in manufacturing industries. The objective of the present study is to assess LSS-CFFs which affect the adaptation of the LSS framework in manufacturing industries. With such a perspective, the leading LSS-CFFs has been identified and selected through a detailed literature review and opinion of various experts. Then, develop the proper model which shows the contextual relationship between identified LSS-CFFs using the ISMMICMAC approach. This study would help industry persons, practitioners, researchers to anticipate the potential model of LSS-CFFs to implement the LSS framework in their industry to achieve continuous improvement and obtain a leading position in a competitive market.

To perform the study, the present study is considered one PVC pipe manufacturing industry located in Chhattisgarh, India for a research setting. The PVC pipe manufacturing industry has been suffering problems related to many faults in the finished product, resulting in wastage of time, money, and material. Due to these excess faults in the manufactured product, the industry was not able to fulfill customer demand. Such a situation continually decreases the rate of customers. To overcome this problem, industry managers were looking to adopt any quality improvement technique which recognizes the root cause of the fault and eliminates them. Managers of the case industry consulted with LSS experts and discussed the above-mentioned problems and asked for possible solutions. Once experts came across problems, they introduced them to the LSS framework and suggested to implement it in their industry. LSS experts discussed the detailed implementation process, cost, training structure, benefits, etc., In last, experts share his experience about framework implementation failure, they discussed the direct adaptation may have a higher chance of failure which lead to several losses such as monetary, customer, stakeholder's loyalty, the brand image of the organization, etc. The experts also suggested, the detailed knowledge of CFFs of LSS prevents implementation failure. Therefore, the study evaluates the CFFs of LSS and develops a structured model that systematically guides the interrelation of failure factors that affect the LSS framework adaptation in manufacturing organizations.

Also, many studies have reported the barriers, failure factors that affect the adaptation of LSS (Yadav and Desai, 2017; Shreedharn et al., 2018; Sunder and Prashar, 2020). The identification itself does not guide practitioners, researchers, managers to prevent such problems; there is a need to develop a hierarchical structural model that develops the interrelation with CFFs and systematically guides to prevent them during the implementation process. The present study captured this gap and motivated authors to provide a solution by conducting a real-life case study. The following research objectives have been developed:

- Identify and select the CFFs which affect the adaptation of the LSS framework in manufacturing industries.

- Identify the interrelationship among those selected CFFs of LSS through developing a structured hierarchical model.

- Classify the nature of CFFs for a better understanding based on their dependence and driving power.

The rest of the paper is systematically organized as follows: the second section discussed the literature reviews from different perspectives. The third section introduced the applied research methodology. The detailed model development procedure with the help of a case study has been discussed in the fourth section. The fifth section includes results and 
International Journal of Industrial Engineering and Operations Management (IJIEOM)

Volume. 3, No. 1, October 2021

discussion followed by theoretical contributions and managerial implications of the research. The sixth section discusses the conclusion of the study followed by research limitations and future work.

\section{Literature Review}

The literature has been reviewed in two perspectives: the first part covers reviews on CFFs of LSS and the second covers literature review on application of the Interpretative Structural Modeling (ISM) approach. The literature search includes the period from 1967 to 2020 .

\subsection{Review on LSS failure factors}

The failure factors were primarily introduced by "Rubin and Seeling" in 1967. The authors have examined the experience of the project manager based on their failure of projects. This study was the origin of assessing failure factors. Then Barker et al. (1983) have been reported the new definition of failure 'the failure occurs due to inadequate concept and system incorporated or used. The other researchers introduced the failure factors, Antony and Desai (2009) reported the failure factors such as Lack of continuous monitoring approach, Internal resistance against culture change, Ineffective training programs, Poor project prioritization, and tool selection in his study. Aboelmaged (2010) introduced the failure factors such as Poor project prioritization and tool selection, Lack of top management involvement, Lack of resources, Narrow view of LSS, Lack of process thinking and process ownership, Lack of LSS project implementation cost estimation. Delgado et al., (2010) reported the lack of knowledge about LSS tools and inappropriate LSS tools selection were leading CFFs that affect the LSS adaptation process in the financial sector. Jeyaraman and Teo (2010) introduced the failure factors such as Lack of employee engagement, Lack of clear vision, Lack of employee participation, Lack of experience in LSS project adaptation, Lack of team autonomy, Ineffective project management, Lack of a clear plan. Psychogios and Tsironis (2012) highlighted the failure factors such as Lack of employee engagement, inefficient management involvement, and awareness, non-availability of reward and recognition by top management, Lack of awareness about LSS practices, techniques, and tools, internal resistance against culture change, Ineffective training programs. Bhasin (2012) introduced the CFFs such as High implementation cost, Lack of top management attitude, Resistance to culture change, Narrow view about LSS tools and practices, Poor communication, Lack of process thinking and process ownership, High implementation cost, lack of a clear plan. Pamfilie et al. (2012) introduced the failure factors such as the non-availability of the reward system in the industry, Lack of management involvement and awareness, lack of awareness about the LSS approach. Antony et al. (2012) highlighted the CFFs such as internal resistance against culture change, Lack of knowledge about LSS practices, Lack of top management involvement, Poor project prioritization, non-availability of required resources (financial, technical, human, etc.). Albliwi et al. (2014) highlighted the major CFFs such as Poor project prioritization and tool selection, Lack of employee participation, Weak deployment infrastructure, Lack of management involvement and awareness, High implementation cost, improper knowledge about LSS practices. Antony et al., (2016) introduced failure factors such as lack of creative thinking, the inefficiency of reward culture, poor communication among staff were leading failure factors for LSS implementation in service organizations. Yadav and Desai, (2017) identified 27 critical barriers that affect the adaptation of the LSS framework in the industry. The study prioritized those barriers using the fuzzy AHP approach. Yadav et al., (2018) have identified 27 LSS barriers and prioritized those using the fuzzy AHP-PROMETHEE approach. The study was highlighted that poor management, poor resources, misalignment of objectives, ineffective performance measurement system were the leading barriers of LSS. Shreedharan et al., (2018) highlighted 44 CFFs through a carried out detailed study of several kinds of literature. The importance of these factors has been identified based on their weight; the weight has been calculated with the help of integrated TOPSIS-SIMOS techniques. Swarnakar et al., (2019b) discussed the failure factors such as lack of top management involvement, lack of monitoring approach, and ineffective training program were leading factors that affect the LSS adaptation in the industry. Hussain et al., (2019) analyzed barriers to deploy a green LSS framework in the construction process. The findings observed the unstable environment, lack of customer awareness, lack of government policy, lack of funds, and lack of leadership are the top five barriers. Sodhi et al., (2019) reviewed 56 articles related to LSS critical failure factors. The study explored the CFFs for LSS in different service and manufacturing sectors. The findings suggested 34 common CFFs such as lack of training, inefficient management involvement, lack of communication, limited resources, etc. Swarnakar et al., (2020a) identified 26 CFFs of SLSS and evaluated their contextual relationship through the integrated TISM-MICMAC approach. The study result reveals that the utilization of this application successfully formed a 13 levels interrelationship based structured hierarchical model of CFFs which can help in the systematic implementation of the SLSS framework in the organization. Sunder and Prashar, (2020) empirically examined the list of LSS critical failure factors that occurred during different deployment stages. The finding of the study observed a pool of CFFs such as inefficient management awareness, absence of employee participation, unclear vision, deficiency in communication, absence of information/data, ineffective project management, wrong tool selection, etc. Swarnakar et al., (2020d) identified 14 leading CFFs of Sustainable LSS and evaluated their 
contextual relationship through the integrated TISM-MICMAC approach. The study result reveals that the utilization of this application successfully formed a 7 levels interrelationship based structured hierarchical model of CFFs which can help in the systematic implementation of the SLSS framework in the healthcare organization.

\subsection{Review on application of the ISM approach}

ISM approach is used to obtain the complex relationships between variables. The concept of ISM was developed by Warfield in 1974. It is a suitable technique to analyze and solve the complex problems related to decision making such as vendor selection problems (Kannan and Haq, 2007). Mandal and Deshmukh, (1994) have selected vendors by utilizing the interpretive structural modeling (ISM) approach. Thakkar et al., (2007) have evaluated the interrelationship between supplier and buyer using the ISM approach. The study was conducted in the Indian automotive component manufacturing industry. Khurana et al., (2010) have identified the information sharing enablers of the supply chain and evaluated the interrelationship between those enablers through integrated ISM and MICMAC approach. Soti et al., (2011) have modeled the various selected barriers of the Six Sigma approach using the ISM approach and classify their nature using the MICMAC technique. Raj, (2008) has modeled the enablers of a flexible manufacturing system using the same approach. Govindan et al., (2012) have analyzed the third party reverse logistic provider and modeled those using a combined ISM-MICMAC approach. Raut et al., (2017) identified CSFs of supply chain management practices through utilizing the ISM technique. The critical success factors were identified in the context of the oil and gas industries' perspectives. Bhanot et al., (2017) have analyzed both enablers and barriers in the context of sustainable manufacturing using the ISM approach. Swarnakar et al., (2019a) have assessed the critical success factors (CSFs) of LSS using the integrated approach ISM-MICMAC. The study was conducted in the manufacturing industry to identify and evaluate the interrelationship between success factors that help to implement the LSS framework.

\subsection{Research gap}

Literatures are evident that the LSS implementation in manufacturing industries provides significant benefits to the organization and helps them to achieve continuous improvement. The successful implementation of LSS frameworks also brings effective cultural changes in the organization. Based on the present case problem, there is a need to identify the leading CFFs that affect the LSS framework deployment process in the manufacturing industries and evaluate the interrelationship between them. The majority of studies reported the pool of CFFs only but very few have prioritized the CFFs or barriers of LSS in the context of manufacturing organizations (Yadav and Desai, 2017; Yadav et al., 2018; Shreedharn et al., 2018; Sunder and Prashar, 2020). The literature presented by the authors has been used the ISM approach for developing the relationships among factors in different perspectives (Thakkar et al., 2007; Kannan et al., 2009; Raut et al., 2017; Bhanot et al., 2017; Swarnakar et al., 2019a). Based on the literature survey and the best of the author's knowledge, no study has been performed on the evaluation of LSS-CFFs using a combined ISM-MICMAC approach in the context of manufacturing industries. The developed model for LSS-CFFs would help manufacturing industries to prepare the strategy for prevention from CFFs during the adaptation of the LSS framework.

\section{Research Methodology}

This study used a combined methodology to assess the CFFs to implement the LSS framework in manufacturing organizations. Thus, the combined approach included a detailed literature review and expert knowledge to identify and select the LSS-CFFs. The literature was searched and reviewed from different databases such as Scopus, Google Scholar, Emerald Insight, Springer, Elsevier related to the LSS-CFFs, LSS framework, and ISM methodology. The opinions of professionals were also been used to gather the initial data. The experts were selected from different manufacturing organizations situated in India are having more than 10 years' experience in the LSS adapted organizations. The relationships among the various selected LSS-CFFs are identified through Interpretive Structural Modeling (ISM) approach. ISM is an emerging modeling approach used to develop and understand the complex relationships among the selected factors. In this process, a set of factors which directly or indirectly related to each other, are systematically structured and formed a model after predicted the structure of complex process issues in a properly designed pattern which implied graphically as well as word. Further MICMAC analysis has been used to classify the CFFs that help to show the nature of the CFFs based on their classification at different levels. The evaluation steps used in this study are clearly shown in figure 1 . 
International Journal of Industrial Engineering and Operations Management (IJIEOM)

Volume. 3, No. 1, October 2021

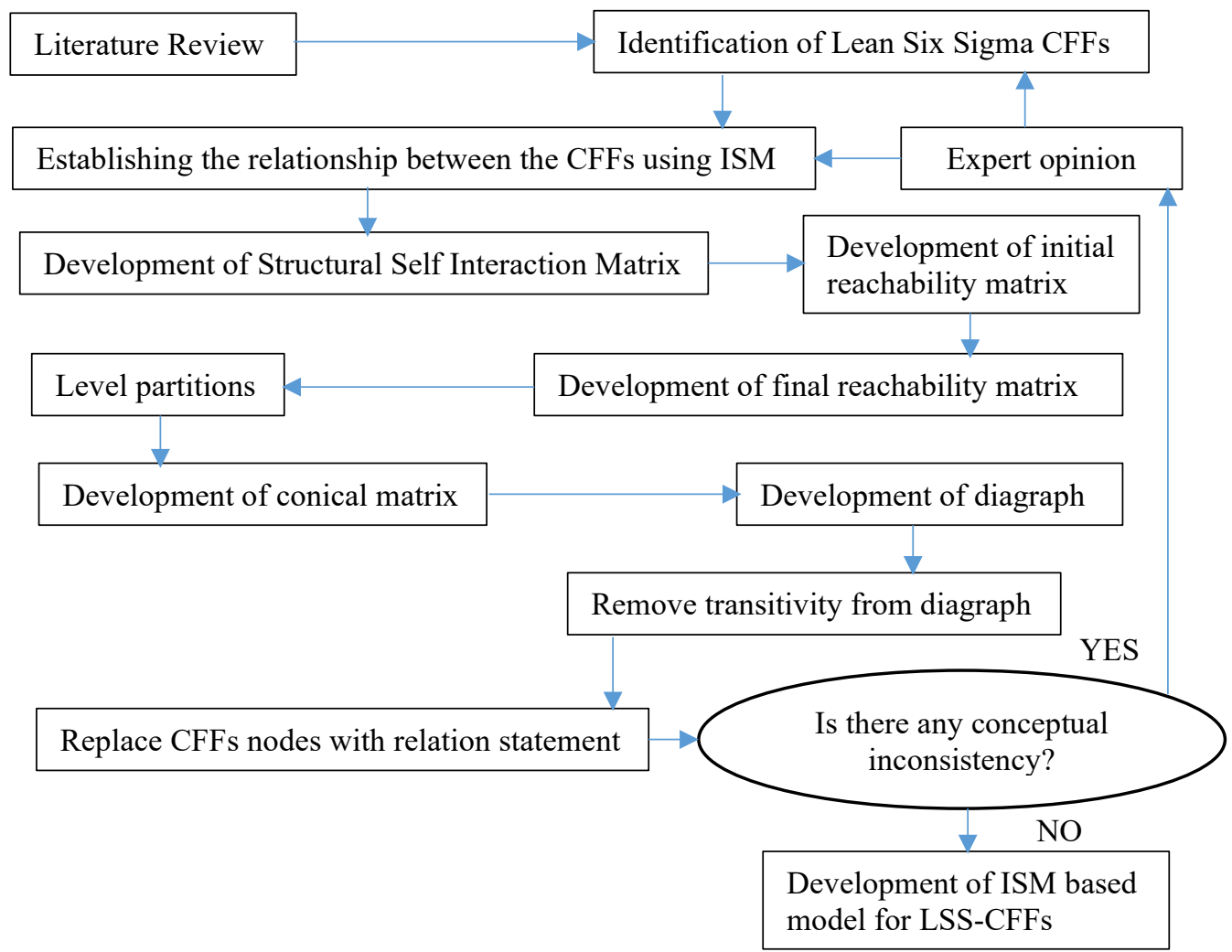

Figure 1. Detailed research methodology

\section{Evaluation of Steps and Model Development}

\subsection{Identification of LSS-CFFs}

The LSS-CFFs have been identified based on the literature review and experts' knowledge. The literature is searched and reviewed from different database sources such as Scopus, Google Scholar, Emerald Insight, Springer, Elsevier related to LSS-CFFs. The experts have been selected from different manufacturing industries from India and their opinions are used to gather initial data related to the case study. The identified CFFs of LSS are presented in Table 1. 
Table 1. Identified LSS critical failure factors

\begin{tabular}{|c|c|c|c|}
\hline $\begin{array}{l}\text { Sl. } \\
\text { No. }\end{array}$ & Critical Failure Factors & Definition & References \\
\hline 1 & $\begin{array}{l}\text { Poor project prioritization and } \\
\text { tool selection (CFF 1) }\end{array}$ & $\begin{array}{l}\text { Selection of wrong activity or path for } \\
\text { the implementation of LSS } \\
\text { framework }\end{array}$ & $\begin{array}{l}\text { Antony and Desai (2009), } \\
\text { Aboelmaged (2010), Albliwi et } \\
\text { al. (2014) }\end{array}$ \\
\hline 2 & $\begin{array}{l}\text { Lack of employee } \\
\text { engagement (CFF 2) }\end{array}$ & $\begin{array}{l}\text { Scarcity of proper meeting } \\
\text { working staff to implement } \\
\text { framework }\end{array}$ & $\begin{array}{l}\text { Psychogios and Tsironis (2012), } \\
\text { Jeyaraman and Teo (2010), } \\
\text { Albliwi et al. (2014) }\end{array}$ \\
\hline 3 & $\begin{array}{l}\text { Weak deployment } \\
\text { infrastructure (CFF 3) }\end{array}$ & $\begin{array}{l}\text { Lacking the required atmosphere and } \\
\text { setup for implementation of the LSS } \\
\text { framework }\end{array}$ & $\begin{array}{l}\text { Pedersen and Huniche (2011), } \\
\text { Albliwi et al. (2014) }\end{array}$ \\
\hline 4 & $\begin{array}{l}\text { Lack of knowledge about } \\
\text { performance metrics (CFF 4) }\end{array}$ & $\begin{array}{l}\text { Absence of skills related to } \\
\text { performance measurement system or } \\
\text { standard of measurement }\end{array}$ & \begin{tabular}{lll} 
Karim & and & \multicolumn{2}{c}{ Arif-Uz-Zaman } \\
$(2013)$, & Roth and Franchetti \\
$(2010)$ & &
\end{tabular} \\
\hline 5 & $\begin{array}{l}\text { Lack of management } \\
\text { involvement and awareness } \\
\text { (CFF 5) }\end{array}$ & $\begin{array}{l}\text { Inappropriate involvement of } \\
\text { management in the industry during } \\
\text { the implementation of the LSS } \\
\text { framework }\end{array}$ & $\begin{array}{l}\text { Kwak \& Anbari (2006), } \\
\text { Psychogios and Tsironis (2012), } \\
\text { Pamfilie et al. (2012), Antony et } \\
\text { al. (2016), Albliwi et al. (2014), }\end{array}$ \\
\hline 6 & $\begin{array}{l}\text { High implementation cost } \\
\text { (CFF 6) }\end{array}$ & $\begin{array}{l}\text { The initial cost is high for the } \\
\text { adaptation of the LSS framework }\end{array}$ & $\begin{array}{l}\text { Bhasin (2012), Chakravorty } \\
\text { (2009), Albliwi et al. (2014) }\end{array}$ \\
\hline 7 & $\begin{array}{l}\text { Lack of recognition and } \\
\text { reward by top management } \\
\text { (CFF 7) }\end{array}$ & $\begin{array}{l}\text { The non-existence of incentives by } \\
\text { the management to encourage } \\
\text { working staffs to implement the LSS } \\
\text { framework }\end{array}$ & $\begin{array}{l}\text { Psychogios and Tsironis (2012), } \\
\text { Pamfilie et al. (2012), Antony et } \\
\text { al. (2016), }\end{array}$ \\
\hline 8 & $\begin{array}{l}\text { Lack of knowledge about } \\
\text { LSS tools, techniques, and } \\
\text { practices (CFF 8) }\end{array}$ & $\begin{array}{l}\text { Improper information and skills to } \\
\text { adopt LSS tools and techniques } \\
\text { during LSS framework adaptation }\end{array}$ & $\begin{array}{l}\text { Antony et al. (2012), Martinez- } \\
\text { Jurado and Moyano-Fuentes } \\
\text { (2014), Psychogios and Tsironis } \\
\text { (2012), Albliwi et al. (2014) }\end{array}$ \\
\hline 9 & $\begin{array}{l}\text { Lack of roadmap to guide the } \\
\text { project Execution (CFF 9) }\end{array}$ & $\begin{array}{l}\text { Deficiency of proper guidelines to } \\
\text { monitor and implementation of LSS } \\
\text { framework }\end{array}$ & $\begin{array}{l}\text { Chakravorty (2009), Albliwi et } \\
\text { al. (2014) }\end{array}$ \\
\hline 10 & $\begin{array}{l}\text { Lack of continuous } \\
\text { monitoring approach (CFF } \\
\text { 10) }\end{array}$ & $\begin{array}{l}\text { Absence of continuous monitoring of } \\
\text { process without any interruption } \\
\text { during LSS implementation }\end{array}$ & $\begin{array}{l}\text { Albliwi et al. (2014), Antony and } \\
\text { Desai (2009) }\end{array}$ \\
\hline 11 & $\begin{array}{l}\text { Internal resistance against } \\
\text { culture change (CFF 11) }\end{array}$ & $\begin{array}{l}\text { Internal struggle/Lacking of support } \\
\text { towards culture change of } \\
\text { organization during the } \\
\text { implementation of LSS framework }\end{array}$ & $\begin{array}{l}\text { Antony et al. (2012a), Antony } \\
\text { and Desai (2009), Bhasin (2012), } \\
\text { Psychogios and Tsironis (2012), } \\
\text { Albliwi et al. (2014) }\end{array}$ \\
\hline 12 & $\begin{array}{l}\text { Ineffective training programs } \\
\text { (CFF 12) }\end{array}$ & $\begin{array}{l}\text { Received unproductive training to } \\
\text { implement LSS framework }\end{array}$ & $\begin{array}{l}\text { Antony and Desai (2009), } \\
\text { Albliwi et al. (2014), Psychogios } \\
\text { and Tsironis (2012), }\end{array}$ \\
\hline
\end{tabular}

\subsection{Selection of Panel Experts}

The LSS experts were selected from different sectors such as manufacturing organizations, academia, and nongovernmental organizations. All experts having a minimum of 10 years of experience in the respective fields and they have already successfully implemented the LSS framework in several organizations. The evaluation process of LSSCFFs has been done with the help of a total of 10 experts, the list of experts and their respective qualifications are mentioned in Table 2 . 
Table 2. List of panel experts

\begin{tabular}{|l|l|l|l|}
\hline $\begin{array}{l}\text { Sl. } \\
\text { No. }\end{array}$ & Designation & Academic qualification & $\begin{array}{l}\text { Experience in the } \\
\text { concerned field }\end{array}$ \\
\hline 1 & Champion & Master in Engineering and Science & 23 years \\
\hline 2 & LSS Master Black Belt & Ph.D. in Production Engineering & 17 years \\
\hline 3 & LSS Black Belt & Master in Mechanical Engineering & 15 years \\
\hline 4 & LSS Black Belt & Master in Industrial and Production Engineering & 12 years \\
\hline 5 & LSS Green Belt & Bachelor in Engineering & 10 years \\
\hline 6 & LSS Green Belt & Bachelor in Technology & 13 years \\
\hline 7 & LSS Green Belt & Bachelor in Technology & 12 years \\
\hline 8 & LSS Green Belt & Bachelor of Engineering & 10 years \\
\hline 9 & Academician & Ph.D. in Industrial Engineering and Management & 16 years \\
\hline 10 & Consultant & Master of Business Administration & 15 years \\
\hline
\end{tabular}

\subsection{Development of Structural Self Interaction Matrix (SSIM)}

The panel experts were consulted to provide input for the development of SSIM to assess the interrelationship between the LSS-CFFs for LSS framework implementation. In this context, various techniques are used to take input from the experts such as brainstorming, interview, nominal group techniques, to develop a contextual relationship among identified CFFs. The relationship has been obtained through ISM principles. The four symbols "V, A, X, O" were used to create the relation between CFFs. Thus, symbol ' $V$ ' represents the "variable ' $i$ ' will help to achieve variable ' $\mathrm{j}$ "; where symbol 'A' represents the "variable ' $\mathrm{j}$ ' will help to achieve variable ' $\mathrm{i}$ "; the symbol ' $\mathrm{X}$ ' represents the "variable ' $\mathrm{i}$ ' and ' $\mathrm{j}$ ' will help to achieve each other", and symbol ' $O$ ' represents the "variable ' $\mathrm{i}$ ' and ' $\mathrm{j}$ ' are unrelated". The frequency analysis is used to select the input for the development of SSIM for the evaluation of LSS-CFFs. The developed SSIM is shown in Table 3.

Table 3. SSIM for assessment of LSS-CFFs

\begin{tabular}{|c|c|c|c|c|c|c|c|c|c|c|c|c|c|}
\hline & & 12 & 11 & 10 & 9 & 8 & 7 & 6 & 5 & 4 & 3 & 2 & 1 \\
\hline 1 & CFF 1 & $X$ & $\mathrm{~V}$ & V & A & X & $\mathrm{V}$ & $\mathrm{O}$ & $\mathrm{V}$ & $\mathrm{V}$ & $\mathrm{V}$ & $\mathrm{V}$ & - \\
\hline 2 & CFF 2 & $X$ & $\mathrm{O}$ & $X$ & A & $\mathrm{X}$ & V & $\mathrm{V}$ & $X$ & $\mathrm{X}$ & $\mathrm{X}$ & - & \\
\hline 3 & CFF 3 & $X$ & $\mathrm{O}$ & $X$ & $X$ & A & $\mathrm{V}$ & $X$ & $\mathrm{O}$ & $X$ & - & & \\
\hline 4 & CFF 4 & A & $\mathrm{O}$ & $\mathrm{O}$ & $X$ & $\mathrm{O}$ & A & $\mathrm{V}$ & $\mathrm{O}$ & - & & & \\
\hline 5 & CFF 5 & V & $\mathrm{O}$ & A & $\mathrm{O}$ & V & $\mathrm{O}$ & V & - & & & & \\
\hline 6 & CFF 6 & $X$ & $\mathrm{O}$ & $\mathrm{A}$ & $\mathrm{V}$ & $\mathrm{O}$ & $\mathrm{V}$ & - & & & & & \\
\hline 7 & CFF 7 & A & $\mathrm{V}$ & $\mathrm{O}$ & A & A & - & & & & & & \\
\hline 8 & CFF 8 & A & $\mathrm{O}$ & A & $X$ & - & & & & & & & \\
\hline 9 & CFF 9 & A & $\mathrm{O}$ & A & - & & & & & & & & \\
\hline 10 & CFF 10 & $\mathrm{~V}$ & $\mathrm{O}$ & - & & & & & & & & & \\
\hline 11 & CFF 11 & $\mathrm{O}$ & - & & & & & & & & & & \\
\hline 12 & CFF 12 & - & & & & & & & & & & & \\
\hline
\end{tabular}

\subsection{Development of initial reachability Matrix (IRM)}

The IRM has been developed with the transformation of SSIM symbols into binary digits. The transformation process depended on the following rules based on ISM principles. Thus substitution of symbols ' $\mathrm{V}$ ', 'A', ' $\mathrm{X}$ ', ' $\mathrm{O}$ ' by digits 1 and 0 with the following rules: 'if (' $i$ ', ' $j$ ') entry in the system is ' $V$ ' then the (' $i$ ', ' $j$ ') entry in the IRM becomes ' 1 ' and ' 0 ' when (' $j$ ', ' $i$ ')"; ' 'if (' $i$ ', ' $j$ ') entry in the system is ' $A$ ', then the (' $i$ ', ' $j$ ') entry in the IRM becomes ' 0 ' and ' 1 ' when (' $j$ ', ' $i$ ')"; "if (' $i$ ', ' $j$ ') entry in the system is ' $X$ ' then the (' $i$ ', ' $j$ ') entry in the IRM becomes ' 1 ' and ' 1 ' when ('j', ' $i$ ')"; 'if (' $i$ ', 
Volume. 3, No. 1, October 2021

' $j$ ') entry in the system is ' $O$ ' then the (' $i$ ', ' $j$ ') entry in the IRM becomes ' 0 ' and ' 0 ' when (' $j$ ', ' $i$ ')'. The developed IRM for assessment of LSS-CFFs is shown in Table 4.

Table 4. Initial reachability matrix (IRM) for assessment of LSS-CFFs

\begin{tabular}{|l|l|l|l|l|l|l|l|l|l|l|l|l|l|}
\cline { 2 - 14 } \multicolumn{2}{c|}{} & 1 & 2 & 3 & 4 & 5 & 6 & 7 & 8 & 9 & 10 & 11 & 12 \\
\hline 1 & CFF 1 & 1 & 1 & 1 & 1 & 1 & 0 & 1 & 1 & 0 & 1 & 1 & 1 \\
\hline 2 & CFF 2 & 0 & 1 & 1 & 1 & 1 & 1 & 1 & 1 & 0 & 1 & 0 & 1 \\
\hline 3 & CFF 3 & 0 & 1 & 1 & 1 & 0 & 1 & 1 & 0 & 1 & 1 & 0 & 1 \\
\hline 4 & CFF 4 & 0 & 1 & 1 & 1 & 0 & 1 & 0 & 0 & 1 & 0 & 0 & 0 \\
\hline 5 & CFF 5 & 0 & 1 & 0 & 0 & 1 & 1 & 0 & 1 & 0 & 0 & 0 & 1 \\
\hline 6 & CFF 6 & 0 & 0 & 1 & 0 & 0 & 1 & 1 & 0 & 1 & 0 & 0 & 1 \\
\hline 7 & CFF 7 & 0 & 0 & 0 & 1 & 0 & 0 & 1 & 0 & 0 & 0 & 1 & 0 \\
\hline 8 & CFF 8 & 1 & 1 & 1 & 0 & 0 & 0 & 1 & 1 & 1 & 0 & 0 & 0 \\
\hline 9 & CFF 9 & 1 & 1 & 1 & 1 & 0 & 0 & 1 & 1 & 1 & 0 & 0 & 0 \\
\hline 10 & CFF 10 & 0 & 1 & 1 & 0 & 1 & 1 & 0 & 1 & 1 & 1 & 0 & 1 \\
\hline 11 & CFF 11 & 0 & 0 & 0 & 0 & 0 & 0 & 0 & 0 & 0 & 0 & 1 & 0 \\
\hline 12 & CFF 12 & 1 & 1 & 1 & 1 & 0 & 1 & 1 & 1 & 1 & 0 & 0 & 1 \\
\hline
\end{tabular}

\subsection{Development of final reachability Matrix (FRM)}

The FRM has been developed after checking the transitivity which occurred during the development of IRM and removes that if there is any, the transitivity has been removed using the following rules. Check the appearance of zero in the IRM and check the transitivity e.g., if CFF 1 leads to CFF 2 is 1 and CFF 2 leads to CFF 3 is also 1 then this implies CFF 1 leads to CFF 3 is 1 . If found any transitivity replace digit ' 0 ' with ' 1 '”. The developed FRM is shown in Table 5.

Table 5. Final reachability matrix (FRM) for assessment of LSS-CFFs

\begin{tabular}{|c|c|c|c|c|c|c|c|c|c|c|c|c|c|c|c|}
\hline & & 1 & 2 & 3 & 4 & 5 & 6 & 7 & 8 & 9 & 10 & 11 & 12 & $\begin{array}{l}\text { Drivi } \\
\text { ng } \\
\text { Power }\end{array}$ & Rank \\
\hline 1 & CFF 1 & 1 & 1 & 1 & 1 & 1 & $1^{*}$ & 1 & 1 & 0 & 1 & 1 & 1 & 11 & 6 \\
\hline 2 & CFF 2 & $1^{*}$ & 1 & 1 & 1 & 1 & 1 & 1 & 1 & 0 & 1 & $1^{*}$ & 1 & 11 & 6 \\
\hline 3 & CFF 3 & 0 & 1 & 1 & 1 & 0 & 1 & 1 & 0 & 1 & 1 & 0 & 1 & 8 & 3 \\
\hline 4 & CFF 4 & $1^{*}$ & 1 & 1 & 1 & 0 & 1 & $1^{*}$ & $1^{*}$ & 1 & 0 & 0 & $1 *$ & 9 & 4 \\
\hline 5 & CFF 5 & $1^{*}$ & 1 & $1^{*}$ & 0 & 1 & 1 & 0 & 1 & 0 & $1^{*}$ & 0 & 1 & 8 & 3 \\
\hline 6 & CFF 6 & $1^{*}$ & 0 & 1 & $1^{*}$ & $1^{*}$ & 1 & 1 & $1^{*}$ & 1 & 0 & 0 & 1 & 9 & 4 \\
\hline 7 & CFF 7 & 0 & $1^{*}$ & $1^{*}$ & 1 & 0 & $1^{*}$ & 1 & 0 & 0 & 0 & 1 & $1 *$ & 7 & 2 \\
\hline 8 & CFF 8 & 1 & 1 & 1 & 0 & $1^{*}$ & $1^{*}$ & 1 & 1 & 1 & $1^{*}$ & 0 & $1 *$ & 10 & 5 \\
\hline 9 & CFF 9 & 1 & 1 & 1 & 1 & 0 & $1^{*}$ & 1 & 1 & 1 & 0 & 0 & 0 & 8 & 3 \\
\hline 10 & CFF 10 & $1^{*}$ & 1 & 1 & 0 & 1 & 1 & 0 & 1 & 1 & 1 & 0 & 1 & 9 & 4 \\
\hline 11 & CFF 11 & $1^{*}$ & $1^{*}$ & 0 & 0 & 0 & 0 & 0 & 0 & 0 & 0 & 1 & $1 *$ & 4 & 1 \\
\hline 12 & CFF 12 & 1 & 1 & 1 & 1 & 0 & 1 & 1 & 1 & 1 & 0 & $1 *$ & 1 & 10 & 5 \\
\hline & $\begin{array}{l}\text { Depende } \\
\text { nce } \\
\text { Power }\end{array}$ & 10 & 11 & 11 & 8 & 6 & 11 & 9 & 9 & 7 & 6 & 5 & 11 & & \\
\hline & Rank & 6 & 7 & 7 & 4 & 2 & 7 & 5 & 5 & 3 & 2 & 1 & 7 & & \\
\hline
\end{tabular}


Table 5 indicated driving and dependence power. The driving power has been calculated by adding all entities presented in each row whereas dependence power is calculated through adding all entities presented in each column. The rank is calculated based on the values of driving and dependence power separately.

\subsection{Level partition}

The level partition for factors is carried out to know about the position of the factors based on their level (Kinker et al. 2020a). The partitions in different levels have been done based on the antecedent and reachability set. The antecedent and reachability set is obtained through the final reachability matrix FRM (Warfield, 1974). The antecedent set containing the LSS-CFF itself and other LSS-CFF elements having in the same column and the reachability set contains the same LSS-CFF element and other LSS-CFF element having in the same row. The intersection includes all common values from both sets. Based on Warfield 1974 "The reachability and interaction values are the same for the factors and have provided the priority during level partition". Thus, in this case, a total, 6 iterations (6 levels) have been performed. In our case, "Weak deployment infrastructure (CFF 3)", "High implementation cost (CFF 6)", "Internal resistance against culture change (CFF 11)" has been identified in the first level. Each iteration is presented one by one, the iterations 1 to 6 for the assessment of LSS-CFFs is shown in Table 6-11.

Table 6. Iteration 1 for assessment of LSS-CFFs

\begin{tabular}{|l|l|l|l|l|l|}
\cline { 3 - 6 } \multicolumn{2}{c|}{} & Reachability Set & Antecedent set & Intersection set & Level \\
\hline 1 & CFF 1 & $1,2,3,4,5,6,7,8,10,11,12$ & $1,2,4,5,6,8,9,10,11,12$ & $1,24,5,6,8,10,11,12$ & \\
\hline 2 & CFF 2 & $1,2,3,4,5,6,7,8,10,11,12$ & $1,2,3,4,5,7,8,9,10,11,12$ & $1,2,3,4,5,7,8,10,11,12$ & \\
\hline 3 & CFF 3 & $2,3,4,6,7,9,10,12$ & $1,2,3,4,5,6,7,8,9,10,12$ & $2,3,4,6,7,9,10,12$ & I \\
\hline 4 & CFF 4 & $1,2,3,4,6,7,8,9,12$ & $1,2,3,4,6,7,9,12$ & $1,2,3,4,6,7,9,12$ & \\
\hline 5 & CFF 5 & $1,2,3,5,6,8,10,12$ & $1,2,5,6,8,10$ & $1,2,5,6,8,10$ & \\
\hline 6 & CFF 6 & $1,3,4,5,6,7,8,9,12$ & $1,2,3,4,5,6,7,8,9,10,12$ & $1,3,4,5,6,7,8,9,12$ & I \\
\hline 7 & CFF 7 & $2,3,4,6,7,11,12$ & $1,2,3,4,6,7,8,9,12$ & $2,3,4,6,7,12$ & \\
\hline 8 & CFF 8 & $1,2,3,5,6,7,8,9,10,12$ & $1,2,4,5,6,8,9,10,12$ & $1,2,5,6,8,9,10,12$ & \\
\hline 9 & CFF 9 & $1,2,3,4,6,7,8,9$ & $3,4,6,8,9,10,12$ & $3,4,6,8,9$ & \\
\hline 10 & CFF 10 & $1,2,3,5,6,8,9,10,12$ & $1,2,3,5,8,10$ & $1,2,3,5,8,10$ & \\
\hline 11 & CFF 11 & $1,2,11,12$ & $1,2,7,11,12$ & $1,2,11,12$ & I \\
\hline 12 & CFF 12 & $1,2,3,4,6,7,8,9,11,12$ & $1,2,3,4,5,6,7,8,10,11,12$ & $1,2,3,4,6,7,8,11,12$ & \\
\hline
\end{tabular}


Table 7. Iteration 2 for assessment of LSS-CFFs

\begin{tabular}{|l|l|l|l|l|l|}
\cline { 3 - 6 } \multicolumn{2}{l|}{} & Reachability Set & Antecedent set & Intersection set & Level \\
\hline 1 & CFF 1 & $1,2,4,5,7,8,10,12$ & $1,2,4,5,8,9,10,12$ & $1,2,4,5,8,10,12$ & \\
\hline 2 & CFF 2 & $1,2,4,5,7,8,10,12$ & $1,2,4,5,7,8,9,10,12$ & $1,2,4,5,7,8,10,12$ & II \\
\hline 5 & CFF 4 & $1,2,4,7,8,9,12$ & $1,2,4,7,9,12$ & $1,2,4,7,9,12$ & \\
\hline 7 & CFF 5 & $1,2,5,8,10,12$ & $1,2,5,8,10$ & $1,2,5,8,10$ & \\
\hline 8 & CFF 7 & $2,4,7,12$ & $1,2,4,7,8,9,12$ & $2,4,7,12$ & II \\
\hline 9 & CFF 9 & $1,2,5,7,8,9,10,12$ & $1,2,4,5,8,9,10,12$ & $1,2,5,8,9,10,12$ & \\
\hline 10 & CFF 10 & $1,2,5,8,9,10,12$ & $4,8,9,10,12$ & $4,8,9$ & \\
\hline 12 & CFF 12 & $1,2,4,7,8,9,12$ & $1,2,5,8,10$ & $1,2,5,8,10$ & \\
\hline
\end{tabular}

Table 8. Iteration 3 for assessment of LSS-CFFs

\begin{tabular}{|l|l|l|l|l|l|}
\cline { 3 - 6 } \multicolumn{2}{c|}{} & Reachability Set & Antecedent set & Intersection set & Level \\
\hline 1 & CFF 1 & $1,4,5,8,10,12$ & $1,4,5,8,9,10,12$ & $1,4,5,8,10,12$ & III \\
\hline 4 & CFF 4 & $1,4,8,9,12$ & $1,4,9,12$ & $1,4,9,12$ & \\
\hline 5 & CFF 5 & $1,5,8,10,12$ & $1,5,8,10$ & $1,5,8,10$ & \\
\hline 8 & CFF 8 & $1,5,8,9,10,12$ & $1,4,5,8,9,10,12$ & $1,5,8,9,10,12$ & III \\
\hline 9 & CFF 9 & $1,4,8,9$ & $4,8,9,10,12$ & $4,8,9$ & \\
\hline 10 & CFF 10 & $1,5,8,9,10,12$ & $1,5,8,10$ & $1,5,8,10$ & \\
\hline 12 & CFF 12 & $1,4,8,9,12$ & $1,4,5,8,10,12$ & $1,4,8,12$ & \\
\hline
\end{tabular}

Table 9. Iteration 4 for assessment of LSS-CFFs

\begin{tabular}{|l|l|l|l|l|l|}
\cline { 3 - 6 } \multicolumn{2}{c|}{} & Reachability Set & Antecedent set & Intersection set & Level \\
\hline 4 & CFF 4 & $4,9,12$ & $4,9,12$ & $4,9,12$ & IV \\
\hline 5 & CFF 5 & $5,10,12$ & 5,10 & 5,10 & \\
\hline 9 & CFF 9 & 4,9 & $4,9,10,12$ & 4,9 & IV \\
\hline 10 & CFF 10 & $5,9,10,12$ & 5,10 & 5,10 & \\
\hline 12 & CFF 12 & $4,9,12$ & $4,5,10,12$ & 4,12 & \\
\hline
\end{tabular}

Table 10. Iteration 5 for assessment of LSS-CFFs

\begin{tabular}{|l|l|l|l|l|l|}
\cline { 3 - 6 } \multicolumn{2}{l|}{} & Reachability Set & Antecedent set & Intersection set & Level \\
\hline 5 & CFF 5 & $5,10,12$ & 5,10 & 5,10 & \\
\hline 10 & CFF 10 & $5,10,12$ & 5,10 & 5,10 & \\
\hline 12 & CFF 12 & 12 & $5,10,12$ & 12 & V \\
\hline
\end{tabular}

Table 11. Iteration 6 for assessment of LSS-CFFs

\begin{tabular}{|l|l|l|l|l|l|}
\cline { 2 - 6 } \multicolumn{2}{l|}{} & Reachability Set & Antecedent set & Intersection set & Level \\
\hline 5 & CFF 5 & 5,10 & 5,10 & 5,10 & VI \\
\hline 10 & CFF 10 & 5,10 & 5,10 & 5,10 & VI \\
\hline
\end{tabular}




\subsection{Development of conical Matrix}

The conical matrix has been developed based on the priority of the obtained factors level and corresponding pairwise relation value of FRM. The matrix was developed by clustering the CFFs of the same level across rows and columns. The arrangement of those levels in the conical matrix is based on their occurrence in the iteration steps. The conical matrix for assessing the LSS-CFFs is shown in Table 12.

Table 12. Conical matrix for assessment of LSS-CFFs

\begin{tabular}{|l|l|l|l|l|l|l|l|l|l|l|l|l|l|}
\cline { 2 - 13 } \\
\hline 3 & CFF 3 & 1 & 1 & 0 & 1 & 1 & 0 & 0 & 1 & 1 & 1 & 0 & 1 \\
\hline 6 & CFF 6 & 1 & 1 & 0 & 0 & 1 & 0 & 0 & 0 & 1 & 1 & 0 & 0 \\
\hline 11 & CFF 11 & 0 & 0 & 1 & $1 *$ & 0 & 0 & 0 & 0 & 0 & 0 & 0 & 0 \\
\hline 2 & CFF 2 & 1 & 1 & $1 *$ & 1 & 1 & $1 *$ & 1 & 1 & 0 & 1 & 1 & 1 \\
\hline 7 & CFF 7 & $1 *$ & $1 *$ & 1 & $1 *$ & 1 & 0 & 0 & 1 & 0 & 0 & 0 & 0 \\
\hline 1 & CFF 1 & 1 & 0 & 1 & 1 & 1 & 1 & 1 & 1 & 0 & 1 & 1 & 1 \\
\hline 8 & CFF 8 & 1 & 0 & 0 & 1 & 1 & 1 & 1 & 0 & 1 & 0 & 0 & 0 \\
\hline 4 & CFF 4 & 1 & 1 & 0 & 1 & 1 & $1 *$ & 1 & 1 & 1 & $1 *$ & 0 & 0 \\
\hline 9 & CFF 9 & 1 & $1 *$ & 0 & 1 & 1 & 1 & 1 & 1 & 1 & 0 & 0 & 0 \\
\hline 12 & CFF 12 & 1 & 1 & 1 & 1 & 1 & 1 & 1 & 1 & 1 & 1 & 0 & 0 \\
\hline 5 & CFF 5 & 1 & 1 & 0 & 1 & 0 & 1 & 1 & 0 & 0 & 1 & 1 & $1 *$ \\
\hline 10 & CFF 10 & 1 & 1 & 0 & 1 & 0 & 1 & 1 & 0 & 1 & 1 & 1 & 1 \\
\hline
\end{tabular}

\subsection{Development of digraph for LSS-CFFs}

The digraph has been developed by examining the direct relationship of identified various LSS-CFFs which affect the successful adaptation of the LSS framework. The relationship has been developed using FRM value. The relationship between the identified variables in the digraph for assessing the LSS-CFFs is shown in figure 2.

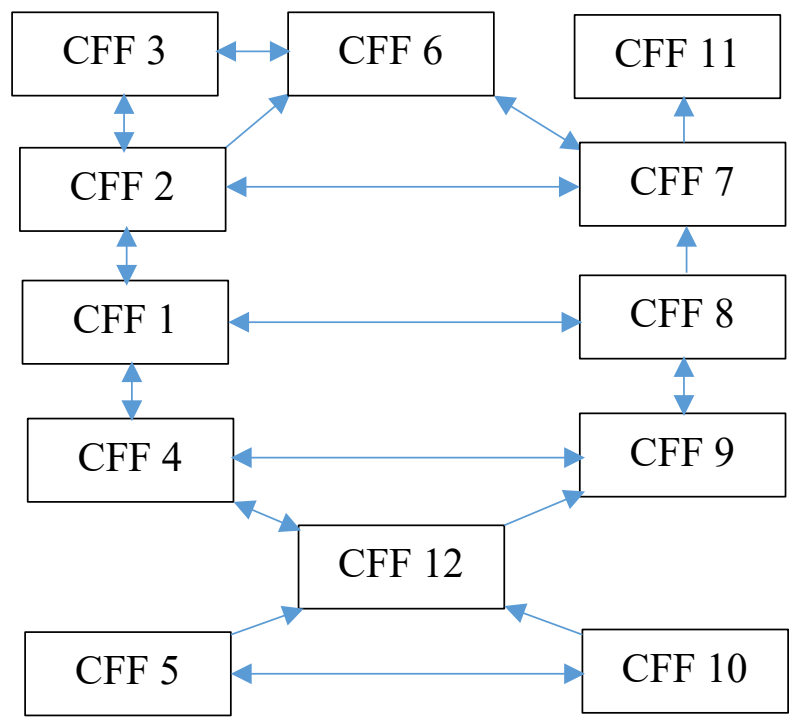

Figure 2. Diagraph of ISM model for assessing LSS-CFFs 


\subsection{Development of ISM based model for LSS-CFFs}

The ISM based model has been developed after eliminating their transitivity from the FRM. The final ISM model has been developed from the conical matrix. If the relationship among all LSS-CFFs has occurred, Then the CFF ' $j$ ' and ' $i$ ' then the relationship arrow pointed out from ' $\mathrm{i}$ ' to ' $\mathrm{j}$ '. The ISM based model for LSS-CFFs is shown in figure 3.

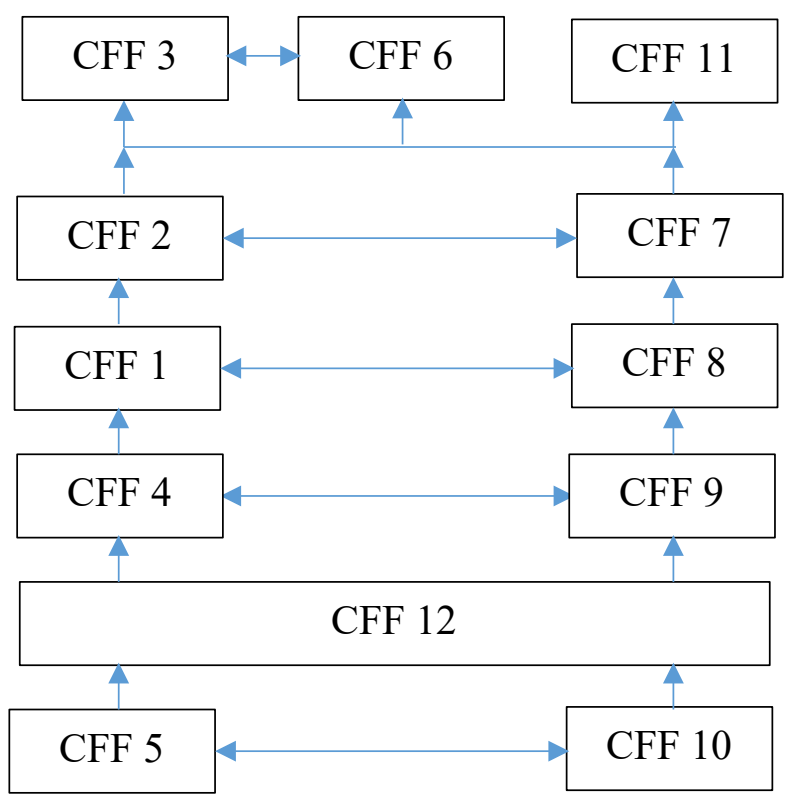

Figure 3. ISM based model for assessing LSS-CFFs

\subsection{MICMAC analysis for assessing CFFs}

The CFFs are categorized into four different categories based on their driving and dependence power with the use of Matrices Impacts Croises Multiplication Appliquee a un Classement (MICMAC) analysis (Mandal and Deshmukh, 1994; Kinker et al., 2020b). The four categories were independence, linkage, dependent and autonomous measure. The categorization is presented in the driving dependence diagram and is shown in figure 4.

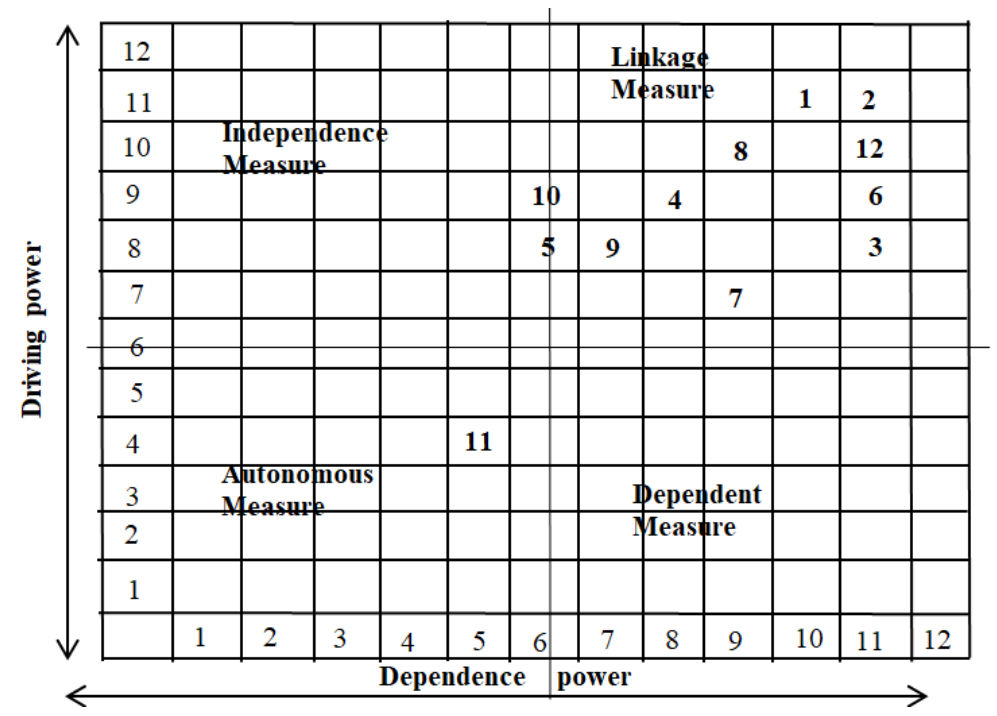

Figure 4. Driving-dependence diagram 


\section{Result and discussion}

To assess the CFFs for LSS framework implementation in manufacturing industries, the study uses the combined approach; this included identification of LSS-CFFs and development of ISM based structural model for evaluating the interrelation between the CFFs. In such a perspective the identification of CFFs has been done through the detailed literature review and experts' knowledge. Then combined ISM-MICMAC techniques have been utilized for obtaining the relationship between those identified CFFs. The inputs for developing the interrelationship were provided by the panel experts belonging to various backgrounds such as industry, academia, and NGOs. The ISM model of LSS-CFFs has been developed for the implementation of the LSS framework which consists of six levels (figure 3). The first level included two factors 'lack of management involvement and awareness (CFF 5)' and 'Lack of continuous monitoring approach (CFF 10)', second-level included one factor 'Ineffective training programs (CFF 12)', the third level included 'Lack of knowledge about performance metrics (CFF 4)' and 'Lack of roadmap to guide the project Execution (CFF 9)', the fourth level included 'Poor project prioritization and tool selection (CFF 1)' and 'Lack of knowledge about LSS tools, techniques, and practices (CFF 8)', the fifth level included 'Lack of employee engagement (CFF 2)' and 'Lack of recognition and reward by top management (CFF 7)', and the sixth level included three CFFs are 'Weak deployment infrastructure (CFF 3)', 'High implementation cost (CFF 6)', 'Internal resistance against culture change (CFF 11)'. The CFF 5 and CFF10 having direct interlink (i.e. CFF5 lead to achieved by the CFF10 and vice versa). The interrelationship entails that the inefficient management involvement affects the continuous monitoring approach whereas a lack of continuous monitoring approach in the organization shows the unawareness of management support. These CFFs helped to achieve the $2^{\text {nd }}$ level CFF (i.e. CFF12). The management inefficiency and lack of proper monitoring system resulted in unawareness about ongoing situations and problems. Such unawareness affects the arrangement of effective training programs for employees. The ineffective training for employees or lack of training facilities in the organization affects the project execution knowledge and metrics that necessary to measure organizational performances. The $3^{\text {rd }}$ level CFFs lead to achieving the $4^{\text {th }}$ level factors i.e. lack of a roadmap to guide project execution and knowledge of performance metrics enhance the chances of poor or wrong project selection and inefficient knowledge of LSS toots due to ineffective training. The knowledge about LSS tools and techniques and their structured implementation process comes from structured training provided by the LSS experts (Swarnakar et al., 2020a). The $5^{\text {th }}$ level CFFs achieved by the $4^{\text {th }}$ level CFFs (i.e. CFF2 and CFF7), because lack of employee encouragement through reward technique and lack of employee engagement comes from a wrong selection of project and lack of knowledge about LSS practices. Lack of a reward system in an organization affects employee engagement for the concerned work, therefore these CFFs having direct interlinks between each other. Finally, these both CFFs and lower level CFFs lead to achieving weak deployment infrastructure, high implementation cost, and internal resistance against culture change at level $6^{\text {th }}$. The developed model shows how one CFF lead to achieving others and affect the LSS adaptation process. The practitioners, decision-makers should focus on primary level factors (CFF5 and CFF10) which automatically eliminate others and help to implement the LSS framework in a case manufacturing organization. Psychogios and Tsironis, (2012) considered lack of top management support and involvement is one of the most critical factors for implementing LSS practices. Also, Yadav et al., (2017) stated that the lack of monitoring approach and inefficiency of management involvement are leading barriers which affect the LSS implementation process.

The result of MICMAC analysis (figure 4) shows that the 'CFF 11' having low driving and dependence power so it comes under 'autonomous measure'. This measure is relatively disconnected from the system but their few links are connected to the system which might be representing very strong. Organization managers do not need to focus on autonomous category factors because it already achieves by concentrating on other factors (Swarnakar et al., 2020b, e). The other remaining CFFs are having strong driving and dependence power and that comes under 'linkage measure'. These factors are unstable within nature, any action on this measure directly affects the other. Therefore, it needs to handle these factors very carefully. In this study, there is no CFF considered under the dependent and independent measure. Psychogios and Tsironis, (2012) derived the same outcome of considering the lack of top management support and involvement as a driver CFFs and highlighted that it facilitated the output of the CFFs. Vinodh and Swarnakar (2015) stated the time and cost estimation is very important for the successful adaptation of the project. The result of the present study guides practitioners and researchers to understand the interrelation among CFFs and provides an idea to remove all those failure factors that can act as hurdles to implement the LSS framework in the organization. The study also suggests managers consider these CFFs before implementing the LSS framework in their organization.

\subsection{Theoretical contributions}

The few studies on manufacturing context explored the identification of CFFs that affect the adaptation of LSS but none of them have developed the interrelation with CFFs. Such an interrelation helps decision-makers, planners to 
systematically guide about the barriers that affect the implementation process and help for further implementation success. Previous studies related to such concerns (Yadav and Desai, 2017; Shreedharn et al., 2018; Sunder and Prashar, 2020) have not developed a structural hierarchical model that is necessary to tackle such CFFs towards the LSS implementation process.

\subsection{Managerial implication of the research}

The present study has highlighted the leading CFFs and then modeled these CFFs in a structural hierarchical model to identify the interrelationship between them using the ISM approach. These leading CFFs may facilitate LSS implementation in manufacturing sectors. There are various insights from an integrated approach of ISM and MICMAC in the concerned sector which summarised as:

- This study highlighted the interrelationship of 12 leading CFFs and represented how these CFFs affect the LSS implementation in manufacturing organizations. It is most important as several researchers focus only on success factors whom they trust to be impactful without examining the effect of failure factors. This research assists the decision-makers to understand the leading CFFs and their interrelationship with each other for the successful deployment of the LSS framework in Indian manufacturing organizations.

- This study directs the LSS implementation in manufacturing organizations by developing a hierarchical structural model of leading CFFs. The developed model provides insight to planners, decision-makers for the removal of those CFFs which affect the deployment process of the LSS framework in manufacturing organizations. The authors of this study believe that this study will inspire the other manufacturing sectors as a demonstration for LSS implementation.

- The CFFs with minimum dependence and maximum driving power act as strategic variables while CFFs having maximum dependence and minimum driving act as performance variables. The authors of this study believe that manufacturing organizations can attain significant benefits by clearly understanding the linkages between these powers for the successful deployment of LSS in Indian manufacturing organizations.

- The result of this study may provide a guideline to managers, decision-makers in strategic and tactical decision making towards LSS implementation in manufacturing organizations.

The developed structural model can be applied in any other manufacturing environment where the problem is similar. If other types of situations occurred then the same method can be followed for CFFs selection and evaluation process.

\section{Conclusion}

LSS is a continuous improvement methodology that eliminates waste from the process and reduces defects occurring in the final output. The successful adaptation of LSS in any manufacturing organization provides a waste and defect-free environment which results in an improvement in quality, production capacity, key metrics, customer satisfaction, etc. The deficiency of proper implementation causes loss of capital, time, loss of a customer, lose the image, etc. To prevent such a situation, need to know factors that affect the successful adaptation of the LSS framework in the manufacturing industry. In this context, this study assesses the CFFs for implementing the LSS framework in the manufacturing industry. Thus, a total of $12 \mathrm{CFF}$ has been identified and selected from the literature review and experts' opinions. The relationship among selected CFFs has been identified through ISM-MICMAC methodology. ISM is a suitable approach to recognizing the interrelation between the variables, the inputs required in this approach were provided by the various experts. The developed ISM model (figure 3) clearly shows the CFFs prioritization based on their obtained six levels. The 'CFF 5', 'CFF 10' occupied the bottom level, and 'CFF 3', 'CFF 6', 'CFF 11' occupied the top level. The MICMAC approach has been used to cluster the CFFs in four different parts based on their driving and dependence power. The developed model shows the initial consideration and elimination of base-level CFFs "lack of management involvement and awareness (CFF 5)' and 'Lack of continuous monitoring approach (CFF 10)' minimize the chance of LSS implementation failure in the case organization. This study will help LSS practitioner, academician to consider such factors with adopting the same methodology to develop the interrelationship based structured model before deploying the LSS framework in their organization. The consideration of CFFs with the development of the model minimizes the chances of failure and helps to implement the LSS framework in any organization.

\subsection{Limitation and future work}

The ISM model for LSS-CFFs has been developed based on the input data gathered from various experts belonging to various sectors such as industrial, non-government organizations, and academia. The model has been developed for one PVC pipe manufacturing organization so the findings obtained from this study may differ for other organizations. This study considered only 12 CFFs for assessment purposes in the case organization. In the future, a greater number of 
CFFs will be considered with different MCDM approaches. The model can also be validated through other tools and techniques.

\section{References}

Albliwi, S., Antony, J., Abdul Halim Lim, S. \& van der Wiele, T. Critical failure factors of Lean Six Sigma: a systematic literature review. Int. J. Qual. Reliab. Manag. 31, 1012-1030 (2014).

Antony, J. \& Desai, D. A. Assessing the status of Six Sigma implementation in the Indian industry: results from an exploratory empirical study. Manag. Res. News 32, 413-423 (2009).

Antony, J., Krishan, N., Cullen, D. \& Kumar, M. Lean Six Sigma for higher education institutions (HEIs) Challenges, barriers, success factors, tools/techniques. Int. J. Product. Perform. Manag. 61, 940-948 (2012).

Antony, J., Setijono, D. \& Dahlgaard, J. J. Lean Six Sigma and Innovation--an exploratory study among UK organisations. Total Qual. Manag. Bus. Excell. 27, 124-140 (2016).

Baker, B. N., Murphy, D. C. \& Fisher, D. Factors affecting project success. Proj. Manag. Handb. 902-919 (1997).

Bhanot, N., Rao, P. V. \& Deshmukh, S. G. An integrated approach for analysing the enablers and barriers of sustainable manufacturing. J. Clean. Prod. 142, 4412-4439 (2017).

Bhasin, S. Prominent obstacles to lean. Int. J. Product. Perform. Manag. 61, 403-425 (2012).

Bhuiyan, N., Baghel, A. \& Wilson, J. A sustainable continuous improvement methodology at an aerospace company. Int. J. Product. Perform. Manag. 55, 671-687 (2006).

Chakravorty, S. S. \& Shah, A. D. Lean Six Sigma (LSS): an implementation experience. Eur. J. Ind. Eng. 6, 118-137 (2012).

Chakravorty, S. S. Six Sigma programs: An implementation model. Int. J. Prod. Econ. 119, 1-16 (2009).

Chen, M. \& Lyu, J. A Lean Six-Sigma approach to touch panel quality improvement. Prod. Plan. Control 20, 445-454 (2009).

Fullerton, R. R., Kennedy, F. A. \& Widener, S. K. Lean manufacturing and firm performance: The incremental contribution of lean management accounting practices. J. Oper. Manag. 32, 414-428 (2014).

Gamal Aboelmaged, M. Six Sigma quality: a structured review and implications for future research. Int. J. Qual. Reliab. Manag. 27, 268-317 (2010).

George, M. L. \& George, M. Lean six sigma for service. (McGraw-Hill New York, NY, 2003).

Govindan, K., Palaniappan, M., Zhu, Q. \& Kannan, D. Analysis of third party reverse logistics provider using interpretive structural modeling. Int. J. Prod. Econ. 140, 204-211 (2012).

Grasso, L. P. Are ABC and RCA accounting systems compatible with lean management? Manag. Account. Q. 7, 12 (2005)

Hussain, K., He, Z., Ahmad, N., \& Iqbal, M. Green, lean, six sigma barriers at a glance: a case from the construction sector of Pakistan. Building and Environment, 161, 106225. (2019).

Jeyaraman, K. \& Kee Teo, L. A conceptual framework for critical success factors of lean Six Sigma: Implementation on the performance of electronic manufacturing service industry. Int. J. Lean Six Sigma 1, 191-215 (2010).

Kannan, G. \& Haq, A. N. Analysis of interactions of criteria and sub-criteria for the selection of supplier in the built-inorder supply chain environment. Int. J. Prod. Res. 45, 3831-3852 (2007).

Kannan, G., Pokharel, S. \& Kumar, P. S. A hybrid approach using ISM and fuzzy TOPSIS for the selection of reverse logistics provider. Resour. Conserv. Recycl. 54, 28-36 (2009).

Karim, A. \& Arif-Uz-Zaman, K. A methodology for effective implementation of lean strategies and its performance evaluation in manufacturing organizations. Bus. Process Manag. J. 19, 169-196 (2013).

Kinker, P., Swarnakar, V., Jain, R., \& Singh, A. R. (2020a). A QFD-TISM approach for service quality improvement in polytechnic education institutes: a case study. Int. J. Applied Systemic Studies, 9(2), 1-29.

Kinker, P., Swarnakar, V., Singh, A. R., \& Jain, R. Identifying and evaluating service quality barriers for polytechnic education: An ISM-MICMAC approach. Materials Today: Proceedings. (2020b). https://doi.org/10.1016/j.matpr.2020.09.129.

Kumar, M., Antony, J., Singh, R. K., Tiwari, M. K. \& Perry, D. Implementing the Lean Sigma framework in an Indian SME: a case study. Prod. Plan. Control 17, 407-423 (2006).

Kwak, Y. H. \& Anbari, F. T. Benefits, obstacles, and future of six sigma approach. Technovation 26, 708-715 (2006).

Lee, K. L. \& Wei, C. C. Reducing mold changing time by implementing Lean Six Sigma. Qual. Reliab. Eng. Int. 26, 387-395 (2010).

Luthra, S., Govindan, K., Kannan, D., Mangla, S. K. \& Garg, C. P. An integrated framework for sustainable supplier selection and evaluation in supply chains. J. Clean. Prod. 140, 1686-1698 (2017).

Mandal, A. \& Deshmukh, S. G. Vendor selection using interpretive structural modelling (ISM). Int. J. Oper. Prod. Manag. $14,52-59$ (1994). 
Martinez-Jurado, P. J. \& Moyano-Fuentes, J. Key determinants of lean production adoption: evidence from the aerospace sector. Prod. Plan. Control 25, 332-345 (2014).

Pamfilie, R., Petcu, A. J. \& Draghici, M. The importance of leadership in driving a strategic Lean Six Sigma management. Procedia-social Behav. Sci. 58, 187-196 (2012).

Psychogios, A. G. \& Tsironis, L. K. Towards an integrated framework for Lean Six Sigma application: Lessons from the airline industry. Total Qual. Manag. Bus. Excell. 23, 397-415 (2012).

Rahbek Gjerdrum Pedersen, E. \& Huniche, M. Determinants of lean success and failure in the Danish public sector: a negotiated order perspective. Int. J. Public Sect. Manag. 24, 403-420 (2011).

Raj, T., Shankar, R. \& Suhaib, M. An ISM approach for modelling the enablers of flexible manufacturing system: the case for India. Int. J. Prod. Res. 46, 6883-6912 (2008).

Raut, R. D., Narkhede, B. \& Gardas, B. B. To identify the critical success factors of sustainable supply chain management practices in the context of oil and gas industries: ISM approach. Renew. Sustain. Energy Rev. 68, 33-47 (2017).

Roth, N. \& Franchetti, M. Process improvement for printing operations through the DMAIC Lean Six Sigma approach: A case study from Northwest Ohio, USA. Int. J. Lean Six Sigma 1, 119-133 (2010).

Sodhi, H. S., Singh, D., \& Singh, B. J. A Review of Critical Factors contributing towards failure of Lean Six Sigma. International Journal of Management, Technology and Engineering, 9(2), 1534. (2019).

Soti, A., Kaushal, O. P. \& Shankar, R. Modelling the barriers of Six Sigma using interpretive structural modelling. Int. J. Bus. Excell. 4, 94-110 (2011).

Sunder M, V., \& Prashar, A. Empirical examination of critical failure factors of continuous improvement deployments: stage-wise results and a contingency theory perspective. International Journal of Production Research, 1(22). 48944915. (2020).

Swarnakar, V. \& Vinodh, S. Deploying Lean Six Sigma framework in an automotive component manufacturing organization. Int. J. Lean Six Sigma 7, 267-293 (2016).

Swarnakar, V., \& Vinodh, S. Lean Six Sigma Project Selection using Analytical Network Process. Proceedings of SOM, 2014. (2014)

Swarnakar, V., kr Tiwari, A., \& Singh, A. R. Assessing Benefits of Lean Six Sigma Approach in Manufacturing Industries: An Indian Context. In Operations Management and Systems Engineering (pp. 127-144). Springer, Singapore. (2019c).

Swarnakar, V., Singh, A. R., \& Tiwari, A. K. Assessment of manufacturing process through lean manufacturing and sustainability indicators: case studies in Indian perspective. In Emerging Trends in Mechanical Engineering (pp. 253-263). Springer, Singapore. (2020b).

Swarnakar, V., Singh, A. R., \& Tiwari, A. K. Assessment of Manufacturing Process Through Lean Manufacturing and Sustainability Indicators: Case. Emerging Trends in Mechanical Engineering: Select Proceedings of ICETME 2018, 253, (2019d).

Swarnakar, V., Singh, A. R., \& Tiwari, A. K. Effect of lean six sigma on firm performance: A case of Indian automotive component manufacturing organization. Materials Today: Proceedings. (2020c). https://doi.org/10.1016/j.matpr.2020.07.115

Swarnakar, V., Singh, A. R., \& Tiwari, A. K. Evaluating Critical Failure Factors for implementing Sustainable Lean Six Sigma Framework in Manufacturing Organization: A Case Experience. International Journal of Lean Six Sigma. (2020a). https://doi.org/10.1108/IJLSS-05-2019-0050

Swarnakar, V., Singh, A. R., \& Tiwari, A. K. Evaluating importance of critical success factors in successful implementation of Lean Six Sigma framework. In AIP Conference Proceedings (Vol. 2148, No. 1, p. 030048). AIP Publishing. (2019a, September).

Swarnakar, V., Singh, A. R., \& Tiwari, A. K. Evaluating the effect of critical failure factors associated with sustainable Lean Six Sigma framework implementation in healthcare organization. International Journal of Quality and Reliability Management. (2020d). https://doi.org/10.1108/IJQRM-07-2020-0243

Swarnakar, V., Singh, A. R., Antony, J., Tiwari, A. K., Cudney, B., \& Furterer, S. A multiple integrated approach for modelling critical success factors in sustainable LSS implementation. Computers \& Industrial Engineering, 106865. (2020e).

Swarnakar, V., Vaidya, S., Tiwari, A. K., \& Singh, A. R. Assessing Critical Failure Factors For Implementing Lean Six Sigma Framework In Indian Manufacturing Organizations. In 3rd IEOM European Conference on Industrial Engineering and Operations Management (pp. 2161-2172). (2019b, July).

Thakkar, J., Kanda, A. \& Deshmukh, S. G. Evaluation of buyer-supplier relationships using an integrated mathematical approach of interpretive structural modeling (ISM) and graph theoretic matrix: the case study of Indian automotive SMEs. J. Manuf. Technol. Manag. 19, 92-124 (2007).

The Hindu, Business Line, WEF ranks India 30th on global manufacturing index. Available at: https://www.thehindubusinessline.com/economy/wef-ranks-india-30th-on-global-manufacturing index/article10032126.ece 
Vinodh, S. \& Swarnakar, V. Lean Six Sigma project selection using hybrid approach based on fuzzy DEMATEL-ANPTOPSIS. 6, 313-338 (2015).

Vinodh, S., Gautham, S. G. \& Ramiya, A. Implementing lean sigma framework in an Indian automotive valves manufacturing organisation: A case study. Prod. Plan. Control 22, 708-722 (2011).

Vinodh, S., Kumar, S. V. \& Vimal, K. E. K. Implementing lean sigma in an Indian rotary switches manufacturing organization. Prod. Plan. Control 25, 288-302 (2014).

Waite, P. J. Save your steps. in Six Sigma Forum Magazine 12, (2013).

Warfield, J. N. Developing subsystem matrices in structural modeling. IEEE Trans. Syst. Man. Cybern. 74-80 (1974).

Yadav, G., \& Desai, T. N. A fuzzy AHP approach to prioritize the barriers of integrated Lean Six Sigma. International Journal of Quality \& Reliability Management. (2017).

Yadav, G., Seth, D., \& Desai, T. N. Application of hybrid framework to facilitate lean six sigma implementation: a manufacturing company case experience. Production Planning \& Control, 29(3), 185-201 (2018).

\section{Biography}

Dr. Vikas Swarnakar is currently working as a Research Scholar in the Department of Mechanical Engineering, National Institute of Technology, Raipur, India. He earned M. Tech in Industrial Engineering and Management from National Institute of Technology, Tiruchirappalli, Tamilnadu, India. He earned his B. Tech in Industrial and Production Engineering from GGU (Central University), Bilaspur, India. He has published more than 20 journals and conference papers in reputed journals. He has published papers in "A" grade journals such as Computers and Industrial Engineering (Elsevier). He is in the article review committee of many journals. Dr. Vikas Swarnakar served as Assistant Professor in JK Engineering College, Bilaspur and Shankaracharya College Bhilai. His research interest includes Lean Manufacturing, Six Sigma, Sustainability, Agile Manufacturing, Supply Chain Management, Optimization, etc. He is a member of IEI, IIE, and IAENG. He is a Certified Lean Six Sigma Black Belt. 